spine disclosed two intradural extramedullary masses located anterior to the spinal cord at the C7-T1 level displacing the cord posteriorly. These two masses had a higher intensity signal compared with CSF on both $\mathrm{T} 1$ and $\mathrm{T} 2$ weighted sequences (fig 1).

The patient was subjected to C6-T1 laminectomy. Before opening the dura, intraoperative sonography showed two separate cystic lesions. After severing the dentate ligaments, the spinal cord was retracted, exposing the cysts. The one behind the $\mathrm{C} 7$ vertebra was attached to the pia of the cord, was ovoid in shape, and partially invaginated into the cord. The second cyst, behind the T1 vertebra, was attached to the dura anteriorly and was pulsatile. It caused no obvious cord compression. These two cysts were extracted and excised from their attachments using an operating microscope.

The patient made an uneventful recovery. The paraesthesia over his chest and right leg disappeared shortly after the operation, whereas weakness and atrophy of both his hands showed gradual but steady improvement during follow up to six months after the operation.

Each cyst measured $1.5 \mathrm{~cm}$ in diameter, had a light blue tint, and contained milky fluid. Histologically, both cyst walls were composed of connective tissue lined by a single layer of ciliated or non-ciliated columnar epithelium. Intracytoplasmic mucin was identified in some of the epithelial lining with alcian blue and mucicarmine, and was positive to a diastase pretreated periodic acid Schiff (DPAS) reaction. Carcinoembryonic antigen was demonstrated immunohistochemically in these cells (fig 2). As the enteric tract is positive for this stain from the second to the sixth month of fetal development, Miyagi et al have reported that the epithelial cells of intraspinal enterogenous cysts respond positively to staining for carcinoembryonic antigen. ${ }^{2}$

Intraspinal enterogenous cysts usually affect young men more than women. They have been found more often in the cervical than in the thoracic or lumbar region. They usually occupy the intradural extramedullary space. ${ }^{3}$ The initial clinical manifestations of our patient were weakness and atrophy of the intrinsic muscles of his right hand for 15 years without any sensory involvement, clinical features rarely seen in the previously documented cases. Woo and Sharr have subgrouped the cysts into two types-the developmental type usually located anterior to the cord in the cervica region and the teratomatous type usually located posterior to the cord around the conus. ${ }^{4}$

Intraoperative sonography showed not only the extent of cord compression, but also the coexistence of a second cyst, which might not have been easily seen during the operation especially when the cyst is anteriorly located and invaginated into the cord.

$$
\begin{array}{r}
\text { I H CHEN } \\
\text { Taipei Municipal Chung-Hsiao Hospital, } \\
\text { Republic of China } \\
\text { K P KAO } \\
\text { I W PENN } \\
\text { D M HO } \\
\text { Veterans General Hospital-Taipei, }
\end{array}
$$
Republic of Chin

Correspondence to: Dr Ih-Hsin Chen Department of Neurosurgery, Taipei Municipa Chung-Hsiao Hospital, 87 Tong-Teh Road Taipei, Taiwan 11502, Republic of China.
1 French BN. Midline fusion defects and defects of formation. In: Youmans JR, ed. Neurological surgery 3rd ed. Philadelphia: WB Saunders Company, 1990:1201-4. Kinjo T, Nakasone S. Enterogenous cyst in the cervical spinal canal. Case report $\mathcal{f}$ Neurosurg 1988;69:292-6.

3 Agnoli AL, Laun A, Schonmayr R. Enterogenous intraspinal cysts. $\mathcal{F}$ Neurosur 1984;61:834-40.

4 Woo PYC, Sharr MM. Childhood cervical enterogenous cyst presenting with hemiparesis. Postgrad Med $¥$ 1982;58:424-6.

Craniopharyngioma: early and long term recurrence after partial removal

There continues to be controversy over whether a craniopharyngioma is best treated by total radical removal or by partial removal combined with evacuation of any cyst. ${ }^{1}$ There is a paucity of data documenting long term survival after 10 years. In this clinic 65 cases of craniopharyngioma have been treated since 1950 , by partial removal and cyst evacuation with no total removals. Twenty nine cases survived more than five years and the cause of death, time to recurrence, and use of further surgery and radiotherapy have been documented in those surviving for more than and less than 10 years. All cases were histologically verified. during the operation or in the early postoperative period. Twelve cases were lost to follow up and 14 cases with less than five years of follow up were excluded from this study.

There was a uniform surgical technique of puncture and aspiration of the cystic component followed by partial removal of
2 Miyagi $\mathrm{K}$, Mukawa J, Mekaru S, Ishikawa $Y$, Ten cases died within the first year, either

the tumour capsule through a subfrontal approach on the right or non-dominant side. The capsule was removed as much as possible within the operative field, but traction of the capsule was not attempted, to avoid damage to the hypothalamic area. Hence, the capsule of the posterosuperior aspect where it attached to the hypothalamic surface was preserved. Visible tumour tissue was removed as much as possible, but hard or invisible tumour tissue was not removed intentionally. Calcification of the tumour was sometimes removed. When recurrence or enlargement of the residual tumour caused such neurological signs as increased intracranial pressure and visual deterioration, reoperation with or without radiotherapy or chemotherapy was performed if possible; in one patient, four times.

To investigate the proliferative potential of patients surviving for less than or more than 10 years, the silver colloid staining method for nucleolar organiser regions (AgNORs) was used as it can be performed on fixed paraffin embedded sections. ${ }^{2}$ Briefly, the staining solution was prepared by dissolving gelatin in $1 \%$ aqueous formic acid at a concentration of $2 \%$ and mixing with twice the volume of $50 \%$ aqueous silver nitrate solution. Paraffin sections $(6 \mu \mathrm{m})$ were incubated in the staining solution at room temperature for 30 minutes in a dark room. The Ag-NORs were then counted under oil immersion at 1000-fold magnification. The NOR number was determined as the mean number of $\mathrm{Ag}-\mathrm{NORs}$ per 200 tumour cells.

Tables 1 and 2 summarise the individual

\begin{tabular}{|c|c|c|c|c|c|}
\hline $\begin{array}{l}\text { Case } \\
\text { No }\end{array}$ & $\begin{array}{l}\text { Age } \\
(y)\end{array}$ & Sex & $\begin{array}{l}\text { Survival } \\
\text { (y) }\end{array}$ & Status & Remarks \\
\hline $\begin{array}{l}1 \\
2 \\
3 \\
4 \\
5 \\
6 \\
7 \\
8 \\
9 \\
10 \\
11 \\
12 \\
13 \\
14\end{array}$ & $\begin{array}{l}27 \\
20 \\
13 \\
57 \\
60 \\
49 \\
21 \\
2 \\
5 \\
31 \\
37 \\
3 \\
2 \\
11\end{array}$ & $\begin{array}{l}\mathbf{M} \\
\mathbf{M} \\
\mathbf{M} \\
\mathbf{F} \\
\mathbf{M} \\
\mathbf{M} \\
\mathbf{M} \\
\mathbf{M} \\
\mathbf{M} \\
\mathbf{F} \\
\mathbf{M} \\
\mathbf{F} \\
\mathbf{F} \\
\mathbf{M}\end{array}$ & $\begin{array}{l}5 \\
6 \\
9 \\
7 \\
7 \\
5 \\
5 \\
7 \\
6 \\
5 \\
6 \\
7 \\
6 \\
5\end{array}$ & 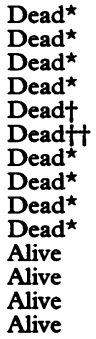 & $\begin{array}{l}\text { Op } \\
\text { Op } \\
\text { Op } \\
\text { Op } \\
\text { Op twice (6 month interval) } \\
\text { Op } \\
\text { Op } \\
\text { Op twice (6 y interval) Rad, Ble } \\
\text { Op } \\
\text { Op twice (5 y interval) Rad } \\
\text { Op Rad, Ble } \\
\text { Op twice (3 y interval) Rad } \\
\text { Op Rad } \\
\text { Op Rad }\end{array}$ \\
\hline
\end{tabular}
patient data of those surviving between five

Table 1 Craniopharyngioma: survival of more than 10 years

\begin{tabular}{llllll}
\hline $\begin{array}{l}\text { Case } \\
\text { No }\end{array}$ & $\begin{array}{l}\text { Age } \\
(y)\end{array}$ & Sex & $\begin{array}{l}\text { Survival } \\
(y)\end{array}$ & Status & Remarks \\
\hline 1 & 11 & M & 39 & Alive & Op \\
2 & 50 & M & 18 & Dead & Op \\
3 & 16 & M & 11 & Deadt & Op \\
4 & 33 & M & 19 & Deadtt & Op twice (2 y interval) \\
5 & 22 & M & 20 & Alive & Op \\
6 & 4 & F & 19 & Alive & Op 3 times $(2,5$ y intervals) \\
7 & 18 & F & 19 & Alive & Op 3 times $(9,10$ y interval) \\
8 & 16 & F & 16 & Alive & Op Rad \\
9 & 36 & F & 15 & Alive & Op \\
10 & 5 & F & 13 & Alive & Op \\
11 & 36 & F & 12 & Alive & Op \\
12 & 44 & M & 10 & Alive & Op \\
13 & 46 & M & 10 & Alive & Op twice (4 month interval) Rad, Ble \\
14 & 16 & M & 19 & Alive & Op 4 times (7 months, 9 y, 2 y interval) Rad, Ble \\
15 & 55 & F & 10 & Alive & Op \\
\hline
\end{tabular}

${ }^{\star}$ Myocardial infarction; fencephalitis ?; †hepatoma; $\mathrm{Ble}=$ bleomycin; $\mathrm{Rad}=$ radiation; $\mathrm{Op}=$ operation.

Table 2 Craniopharyngioma: survival of between five and 10 years

^Brain tumour; theart disease; Hrectal cancer; Ble = bleomycin; Rad = radiation; Op = operation. 
and 10 years (group B) and those surviving for more than 10 years (group $A$ ). The longest period of follow up in Group A was 39 years with a mean follow up period of 16.7 years. In group A there were three deaths, of which two were due to unrelated causes. One year before the death of case 3 , he presented with a high fever and turbid CSF was obtained by lumbar puncture. Encephalitis Japonica was diagnosed, he was given no specific treatment, and was discharged from hospital with unsteadiness of gait and frequent convulsive seizures. One year later he complained of sudden headaches and convulsive seizures. He lost consciousness and died and there was no necropsy.

In group $B$ (14 cases who survived between five and 10 years) 10 had died, eight due to recurrent tumour and two due to unrelated causes. The average age at operation and male/female ratio was $27 \cdot 2$ years and 8/7 in group $A$ and $27 \cdot 1$ years and $10 / 4$ in group $B$. The same surgical technique were used in both groups with 10 of 15 cystic tumours in group $A$ and nine of 14 in group B. Histologically, five cases were adamantinomatous, seven were squamous, and three were not determined in group A, and in group B six were adamantinomatous, six squamous, and two undetermined. The NOR number was determined in 19 cases from their paraffin embedded specimens. All cases had a low proliferative potential (NOR 1.76 (SD $0 \cdot 21$ ) with no difference between the groups (group A $1.73(0.13), 10$ cases; group B $1 \cdot 80(0 \cdot 27)$, nine cases).

It is well known that optic or hypothalamic glioma, cerebellar astrocytoma, ganglioglioma, and some non-glial benign tumours display spontaneous cessation of their growth after an active proliferative growth period but such a phenomenon has not been documented for craniopharyngioma. Among the 15 cases who survived more than 10 years in our series, there was no death due to tumour recurrence or regrowth. By contrast, among those 14 cases in group B with less than 10 years' survival, 10 patients died due to recurrence of the tumour. There are many statistical survival studies for craniopharyngioma but few dealing with long term survival. ${ }^{3-6}$ Each of these series suggests that there is a low risk of recurrence once patients survive for 10 years. For example, in the series of Yasargil et al, patients surviving 11 to 22 years after primary surgery, no death occurred in 30 children and 33 adults$90 \%$ of these cases underwent total removal. Jose et al reported the follow up results of limited surgery and radiation therapy in 173 cases of craniopharyngioma with a median follow up of 12 years. The 10 and 20 year progression free survival rates were $83 \%$ and $79 \%$ and actuarial 10 and 20 year survival rates were $77 \%$ and $66 \%$.

In conclusion, our study supports other evidence in the literature that there may be spontaneous reduction in the active proliferating potential of some craniopharyngiomas that is not predicted by the Ag-NOR technique. Of course, some craniopharyngiomas may always have a low proliferative potential and it is patients with these who survive for more than 10 years. Our data lend support to the policy of subtotal removal and subsequent adjuvant therapy in selected patients but a method for defining this subgroup remains unresolved.

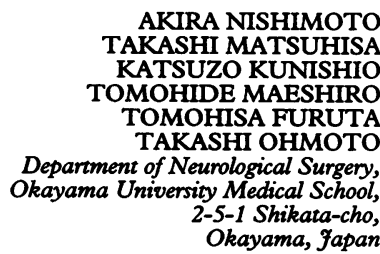

Correspondence to: Dr Akira Nishimoto.

1 Fischer EG, Welch $\mathrm{K}$, Shillito $\mathrm{J} \mathrm{Jr}$, et al Craniopharyngiomas in children. Long-term effects of conservative surgical procedure combined with radiation therapy. $f$ Neurosurg 1990;73:534-40.

2 Maeshiro T, Matsuhisa T, Shigematsu H, et al. Nucleolar organiser regions in gliomas. The relationship to proliferative capacity and prognosis. Brain Tumour Pathology (official Journal of the Japan Society of Brain Tumour Pathology) 1991;8:205-7.

3 Sasaki M, Shitara N, Takakura $K$, et al. Treatment of recurrent craniopharyngioma. Neurol Surg (Tokyo) 1988;16:395-401. (In Japanese.)

4 Yasargil MG, Curcic M, Kis M, et al. Total removal of craniopharyngiomas. Approaches and long-term results in 144 patients. and long-term results

5 Carmel PW, Antunes JL, Chang $\mathrm{CH}$ Craniopharyngiomas in children. Neuro surgery 1982;11:382-9.

6 Jose CC, Rajan B, Ashley S, et al. Craniopharyngioma. Long term results following limited surgery and radiotherapy [abstract]. Br F Cancer 1991;64:7.

\section{Psychosocial factors in chronicity of epilepsy}

Research has shown that after a recent diagnosis of epilepsy psychosocial effects are closely related to the severity of the medical condition and the recency of the last seizure, ${ }^{1}$ suggesting that the stigmatising effect of the diagnosis cannot be viewed as the only or even the main predictor of psychosocial distress. Therefore, we must consider other factors. In this study we sought to explore the effect of chronicity. A comparative study was conducted, based on a validated psychosocial inventory, ${ }^{2}$ of two groups of 62 subjects. These groups were matched for age (range between 17 and 57), sex, and employment type; duration of full time employment was similar as was tenure in current job. The chronic sample had a history of epilepsy spanning an average of 11 years and a minimum of five years. The chronic group was matched with respondents to the National General Practice Survey of Epilepsy (NGPSE) ${ }^{3-5}$ drawn from a base of 594 patients registered by 275 primary care practices across the United Kingdom. The recently diagnosed sample had a history of epilepsy spanning a maximum of three years. The NGPSE is a population based national cohort study following up patients from the time of their first epileptic seizure. The importance of the NGPSE has been the ability to gather unbiased and comprehensive information on an unselected population based on prospective consecutive cases.

All patients in the chronic group had experienced more than 20 seizures. The recently diagnosed group also included some patients who had experienced large numbers of seizures but over $50 \%$ of the group had experienced three or fewer seizures at the time of data collection. The chronic patients were more likely to be registered disabled $(p<0.01)$, to have informed their employer of their epilepsy $(p<0.05)$, and to have had a seizure in public $(p<0.01)$.
Moderate or severe problems in adjustment of patients with a diagnosis of epilepsy

\begin{tabular}{|c|c|c|c|}
\hline & & $\begin{array}{l}\text { Recent } \\
\text { diagnosis } \\
(\%)\end{array}$ & $\begin{array}{l}\text { Chronic } \\
\text { epilepsy } \\
(\%)\end{array}$ \\
\hline $\begin{array}{l}\text { A1 } \\
\text { A2 } \\
\text { A3 }\end{array}$ & $\begin{array}{l}\text { Acceptance of the diagnosis } \\
\text { Fear of having seizures } \\
\text { Fear of stigma affecting }\end{array}$ & $\begin{array}{l}26 \\
75 \\
48\end{array}$ & $\begin{array}{l}65^{\star} \\
69 \\
53\end{array}$ \\
\hline A4 & $\begin{array}{l}\text { Lack of confidence about } \\
\text { the future }\end{array}$ & 24 & $68^{\star}$ \\
\hline A5 & $\begin{array}{l}\text { Lack of confidence about } \\
\text { travelling }\end{array}$ & 15 & $39 *$ \\
\hline $\begin{array}{l}\text { A6 } \\
\text { A7 }\end{array}$ & $\begin{array}{l}\text { Adverse effect on social life } \\
\text { Adverse effect on leisure } \\
\text { pursuits }\end{array}$ & $\begin{array}{l}29 \\
27\end{array}$ & $\begin{array}{l}62^{\star} \\
66^{\star}\end{array}$ \\
\hline A8 & $\begin{array}{l}\text { Change of outlook on } \\
\text { life/self }\end{array}$ & 29 & $67^{\star}$ \\
\hline $\begin{array}{l}\text { A9 } \\
\text { A1 }\end{array}$ & $\begin{array}{l}\text { Difficulty with the family } \\
\text { o Attitudes to taking } \\
\text { medication }\end{array}$ & $\begin{array}{l}21 \\
35\end{array}$ & $\begin{array}{l}32 \\
37\end{array}$ \\
\hline A1 & $\begin{array}{l}1 \text { Attitude to the medical } \\
\text { profession }\end{array}$ & 26 & 41 \\
\hline & 2 Depression or emotional & 26 & $43^{\star}$ \\
\hline & $\begin{array}{l}3 \text { Feeling of increased social } \\
\text { isolation }\end{array}$ & 27 & $58^{\star}$ \\
\hline & 4 Lack of energy/lethargy & 29 & $53^{\star}$ \\
\hline
\end{tabular}

${ }^{\star} \mathrm{p}<0.05$

The table shows the percentage of patients who indicated a moderate or severe problem of adjustment in each of the 14 areas comprising the psychosocial inventory.

Variable means were compared with $t$ tests. A significance level of $p<0.05$ was taken to indicate an important difference between groups.

Clearly, epilepsy, or at least having seizures, can be very distressing for the patient; the inventory not surprisingly showed that most patients with epilepsy have problems of psychosocial adjustment. Only in one area, however, did significant difficulties occur in more than $50 \%$ of the newly diagnosed group, this was the fear of seizures; in the chronic group, difficulties occurred in more than $50 \%$ of patients in nine of the 14 areas. The chronic group were more worried about their future, had a more negative outlook on life, had problems in relation to social life and leisure activities, and were more likely to feel socially isolated.

Although these findings clearly show that chronicity has an adverse effect on adjustment to epilepsy overall, the following areas were not affected: fear of stigma in employment, attitudes towards the medical profession, attitudes towards taking medication, and difficulties with the family. In these areas, seemingly unaffected by the experience of having epilepsy over a period of time or by the experience of a larger number of seizures, other dynamics must be involved in causing problems with adjustment, for instance the effect of the stigma of diagnosis. In different patients, however, factors vary widely and responses to the condition vary in a complex manner. Interventions, therefore, intended to improve psychosocial adjustment, require a high degree of complexity and flexibility.

The findings from this study are important for two reasons: firstly, they illustrate that a potent factor affecting psychosocial adjustment is chronicity; secondly, they emphasise that in most areas stigma is not "inherent" in the condition, and furthermore that there are wide individual variations. We have focused on chronicity but there are of course other factors involved in the process of adjustment. The problems of psychosocial adjustment are clearly relevant 